\title{
Justificación por la fe \\ y vida amenazada de los pobres. \\ Ensayo de reconstrucción teológica
}

\section{Elsa Tamez, \\ Departamento Ecuménico de Investigación (DEI), \\ San José, Costa Rica.}

\section{De la lectura biblica a la relectura teológica}

No podemos repetir las mismas palabras que Pablo propuso a sus comunidades. Su experiencia de la vida, de Dios, su seguimiento de Jesús de Nazareth, su coyuntura histórica y la incipiente comunidad cristiana difieren de la nuestra. Estamos en otro tiempo, otra siuación, otra experiencia eclesial.

No obstante, Dios no ha dejado de revelarse. La vida de Jesucristo, su muerte y resurrección que leemos en las Escrituras, y su palabra que continúa revelándose a través de nuestras realidades, siguen siendo fuente de inspiración para ser reinterpretadas con miras a dar vida a todo ser humano.

El apóstol retomó el kerygma y tradiciones (bautismales, cúlticas, expresiones dominicales) ya existentes de las comunidades y las reinterpreló a partir de su nueva situación $n^{1}$. Nosotros también vamos a retomar aspectos centrales del pensamiento de Pablo sobre la justificación por la fe, para reinterpretarlos a la luz de nuestra realidad latinoamericana. Pablo ha leído el evento de Jesucristo desde su propia perspectiva. Hemos aprendido cómo él vivió e interpretó su fe en Jesucristo, y como reelaboró el tema de la justificación. Nos toca ahora retomar nuevamente el kerygma, es decir, el mensaje acerca de la vida, muerte y resurrección de Jesús, y, con la ayuda de Pablo, reinterpretar, profundizar y tratar de avanzar en su propuesta de la justificación por la fe para nosotros hoy. Sin este esfuerzo, el mensaje de la justificación no será relevante, porque no responderá a la necesidad del hombre y la mujer de nuestro continente.

Ya la lectura que hemos hecho de Pablo ha sido condicionada por nuestros ojos de latinoamericanos, nuestra experiencia de Dios y las exigencias pastorales actuales. Pero aún así, la lectura necesita variaciones por varios motivos. Uno, que es obvio: hoy día no está presente la tensión teológica entre judaizantes o 
judfos cristianos y paganos convertidos, o entre gnosticos y Pablo. Otro, nuestra realidad socio-económica y política es diferente. Además, hay a nuestras espaldas toda una lectura que la tradición cristiana ha hecho de esta doctrina y que forma parte del deposito de la fe de los fieles.

Sin embargo, por la manera como Pablo interpreta el mensaje del evangelio, y por el mismo contenido de su mensaje, observamos varios aspectos centrales que debemos considerar en nuestro ensayo de reconstrucción teológica. Uno de ellos es la preocupación por la vida de las comunidades cristianas como precedente al discurso teológico, y el otro, cieros aspectos que estimamos fundantes de sus afirmaciones sobre la justificación.

Con respecto al primero, habria que tener presente que su argumentación teológica es inmediatamente posterior a la vida concreta de la comunidad cristiana. Es decir, su reinterpretación teórica de la ley, del pecado, de la justicia, de Dios y de la justificación viene después de entrar en diálogo profundo con las comunidades de fe primitivas, en el marco de la vida cotidiana. En dichas comunidades abundan los conflictos, los sufrimientos, las preocupaciones, los malentendidos, las alegrias y las esperanzas, todo ello a nivel teológico y social. Su misma praxis como seguidor de Jesús lo lleva a elaborar una teología sobre el pecado, la justicia y la gracia. Considerar este momento en la reflexión teológica de Pablo es básico para una reinterpretación actualizada. Porque si tomamos en cuenta sólo el plano abstracto de lo que supuestamente dijo sobre la gracia o la justificación, por ejemplo, caemos fácilmente en disputas muchas veces sin sentido, como ha sucedido en la historia del pensamiento cristiano. Los personajes blblicos que hablan y a quienes se habla en un contexto determinado son quienes han de dar razón de los postulados teológicos.

Pablo escribe a comunidades que ya son creyentes; conocen a Jesucristo e intentan vivir una vida nueva. Creen que han sido lavados de sus pecados, santificados y justificados o hechos justos en el nombre del Seffor Jesucristo y el Espíritu de Dios (1Co 6.11; ver 1Co 1,30). De manera que no se trato aquí en primera instancia de presentar el evangelio para que se convirtieran de sus pecados y creyeran en Jesús. Ya habían sido bautizados (Ro 6, 3). Habria que ir entonces más allá y percibir ciertos aspectos fundantes de sus afirmaciones teológicas, que nos puedan servir de claves para nuestra lectura de la justificación hoy.

No se pueden asegurar con exactitud las intencionalidades o inquietudes de un autor detrás de su discurso, pero indicios presentes en el texto, la situación de su contexto e incluso el aporte del lector actual desde su perspectiva particular ${ }^{2}$ nos llevan a deducirlas. Sehalamos cuatro aspectos que consideramos fundantes.

\section{a. Inclución del excluido en el pueblo de Dios}

Si Pablo hizo enfasis en que la justificación es por fe y no por las obras de la 
ley, mucho tiene que ver la tensión teológica candente en ese momento. Algunos sectores judeo-cristianos exiglan la circuncisión y el cumplimiento de varias observaciones de la ley a todo aquel que quisiera tener acceso a las promesas de Dios (dadas a Abraham y su descendencia) y pertenecer a su pueblo. Pablo, por su misión con los gentiles, gente excluida por vivir fuera de la ley judaica, afirma que la ley es incapaz de justificar al ser humano delante de Dios. Dios, en Jesucristo, su vida, su muerte en la cruz y resurrección, había hecho granitamente lo que el ser humano no podia hacer por sí mismo: ser justo. Al hablar de justificación por la fe, Pablo coloca en un plano de iguales a todo los pueblos (todos pecaron, todos son justificados por fe).

Esto es cierto en cuanto a la disputa teológica muy concreta que surgió de las comunidades cristianas primitivas. Pero esta lógica que insiste en la inclusión del excluido cuando se es justificado por fe, lleva a otros niveles, además del religioso. Ya desde su punto de partida está presente la dimensión cultural (culura judía y otras culturas). Pablo mismo cruź, de manera espontánea, la barrera de lo propiamente judio para llegar a aspectos sociales y de género; por eso tendrí que afirmar que en Cristo no hay ni amo ni esclavo, ni mujer ni varón (Ga 3, 28), reconociendo asi otras dos desigualdades entre los seres humanos. La misma realidad de la injusticia convertida en pecado, que describe en Romanos 1-2 otra vez, en toda su crueldad concreta, en 8, 18-38, obliga a ampliar la categoráa de exclusión a la dimensión económica, política y cultural.

\section{b. Hacer conciencia de la ausencia de justicia verdadera o del verdadero co- nocimiento de Dios}

En otro plano distinto al anterior, pero articulado en el sentido (ligado a la vida cotidiana de todos los seres humanos del primer siglo), percibimos que Pablo fue impactado por la desigualdad socio-conómica del imperio romano. En su teologia sobre el pecado (adikia-hamartia) y la justicia de Dios y la justificación (Ro 1-3) no menciona explícitamente el imperio; habla de las impiedades e injusticias de los hombres que encerraron la verdad en la injusticia $(1,18)$, y de que no habla nadie capaz de hacer justicia. Pero un estudio de la situación romana desde la perspectiva de los pobres hace inmediatamente la ligazon entre el poder del pecado y la situación socio-económica; entre la justificación de Dios y la justicia del imperio, entre la gracia de Dios que otorga su justicia como don (frente a la imposibilidad práctica del ser humano de realizarla) y el mérito de status, riqueza y poder que rige la ley imperial.

Creemos que Pablo ve en el sistema del imperio romano un poder estructural económico, político y militar, imposible de confrontar. Por eso cobra las dimensiones de una estructura de pecado (hamartia) que lleva a la muerte. Lo ve como un sistema que bajo las apariencias se presenta como el protector y pacificador de las provincias, pero que esconde en su seno la práctica de injusticias, la 
avaricia de poseer siempre más y de sentirse honrado y admirado por los demás. Para Pablo, esto es ausencia o desconocimiento de Dios, idolatria pura.

Esta ausencia de justicia-ausencia del Dios verdadero, que para Pablo es idolatrí, lo llevó a teologizar sobre el pecado desde Adán. El imperio romano no era la primera ni la única experiencia de dominación de los pueblos; por eso, tiene que haber algo más profundo en el interior del ser humano que lo hace responsable de las injusticias, que se enreda en ellas y que sigue creando por sus mismas prácticas y estructuras incontrolables que esclavizan a los seres humanos.

Pablo no percibe en su tiempo una justicia que tuviera el sello de la verdad. Los judíos pensaban que cumpliendo la ley hacían justicia verdadera, pero Pablo prueba lo contrario: quieren hacer justicia regidos por la ley, y su resultado es la injusticia (Ro 2, 21-23). ¡Las autoridades matan a Jesús siguiendo la ley! El pecado, pues, también se sirve de ésta.

c. Dar seguridad a las comunidades anunciando la revelación de la justicia de Dios para beneficio de todos

Pablo, dijimos, escribe a comunidades que ya son creyentes y bautizadas, y que supuestamente llevan una vida nueva. Sin embargo, su medio les es hostil: padecen hambre y sufren opresiones y discriminaciones (Ro 8, 35-37).

Ya que no había posibilidad objetiva ni subjetiva de hacer justicia por los propios medios en un mundo injusto dominado por el pecado, el anuncio de la justicia de Dios aparece como una gran noticia. Pablo no hace más que recordarla, porque esa justicia llegó con Jesús: su vida, su muerte y su resurrección. Al recordarla da seguridad y confianza a la comunidad cristiana.

Y no sólo eso, sino que abre el horizonte de la esperanza, porque gracias a la justicia gratuita de Dios que hace justo al ser humano a pesar de ser pecador, las comunidades pueden sobreponerse con valentía haciendo justicia, aun yendo contra la corriente ${ }^{3}$.

Pablo llega a la conclusión de que, frente a la precariedad de la vida y la imposibilidad humana de sobreponerse a la injusticia de la que es víctima y responsable, la justicia de Dios capacita a los seres humanos para que sean hacedores de justicia verdadera. Jesús fue el primero, y por él todos tienen acceso a esa gracia, aun los agentes victimarios, si son capaces de creer al Dios que resucita a los muertos (Ro 4, 24s). Esta fe en lo imposible (Ro 4, 19) les fortalece en su existencia cotidiana, luchas y peligros (ver 1Co $15,31 \mathrm{~s}$ ).

Como se puede observar, la intención principal de Pablo no es la de contraponer la iniciativa de Dios frente a la del ser humano en la acción de justicia (aún cuando la recuerda a menudo en sus carlas), ni las obras a la fe. Al partir de la realidad concreta y de su visión antropológica del ser humano como ser 
frágil, Pablo no ve salida posible para la realización de la criatura por sus propios méritos. Está hablando simplemente en términos realistas; por eso tiene que pensar en un Dios que por ser justo y amoroso no permite que los seres caigan en sus propias redes y hagan caer a otros hacia la muerte. Para Pablo, Dios ha de intervenir en la historia anunciando la nueva de la transformación de los seres humanos en hermanos y sujetos que hacen justicia, gracias a la le de Jesucristo y al poder de Dios de resucitar los muertos.

\section{d. Apelar a una fuerza superior en el ser humano que tiene fe para hacer frente al mundo injusto}

Las comunidades cristianas en el tiempo de Pablo eran insignificantes desde todo punto de vista (social, cultural, religioso y militar). Pablo, sin embargo, afirma a los cristianos de Roma que si Dios esta con ellos nadie puede contra ellos (Ro 8, 31). Nadie los separará del amor de Cristo, ni la espada, ni el hanbre, ni la persecución, ni la opresión $(8,35 s)$.

Dijimos que el intenta dar seguridad y confianza a las comunidades, recordándoles la revelación de la justicia de Dios en la historia por medio de Jesucristo. Pero esa no era la única finalidad de Dios. Importante era su efectividad: que se cumpliera en los que siguen una conducta según el espiritu (Ro 8, 4). En otras palabras, que esa justicia fuera lograda por los que creen que Jesús fue resucitado y que "reproducen su imagen" $(8,29)$. El camino de la justicia es la fe, como la que Jesús tuvo. Pablo usa el verbo dikaioo, "justificar", para expresar el don de Dios de posibilitar que las personas hagan justicia.

Pablo interpela la fuerza de lo divino en lo humano, ya que cuando los seres humanos acogen el don de la justicia por fe, la divinidad forma parte de ellos, pues viven en Cristo o están en Cristo, y por consiguiente, sus pensamiento, actitudes y acciones siguen la lógica de Dios. El pensamiento de Pablo en esta lfnea lo lleva a afirmar que tales creyentes son hijos de Dios, sus herederos y aun, los coherederos de Cristo. Parece que es importante para Pablo que el bautizado reconozca la fuerza de su espíritu y del Espíritu que se une a él para testimoniar que tiene el poder de Dios porque es hijo libre de el (8, 15-16). Al ser justificado por Dios, deja de ser esclavo de la ley y del pecado y pasa a ser hijo de Dios y seffor de la historia $(5,17)$.

Estos son los cuatro aspectos fundantes de la justificación en Pablo que recomaremos para nuestro intento de reconstrucción de la justificación por la fe.

\section{Justificación por la fe y vida amenazada de los pobres}

\section{a. Ley de exclusion, reino de muerte}

Para la relectura de la justificación desde America Latina partimos de la vida amenazada de los pobrest, una tragedia provocada por un proyecto humano que, 
por su espítiru de acumulación, no está orientado a cubrir las necesidades básicas para que las mayorías puedan vivir. Como el proyecto se orienta bajo la exigencia de elección y preferencia, excluye en su planeamiento, un vasto sector de seres humanos. La vida de éstos se vuelve vulnerable, está amenazada permanentemente hasta que la lógica de este proyecto se reoriente hacia la satisfacciơn de las necesidades vitales de lodos.

Los pobres, que son los excluidos por no tener acceso a los bienes de consumo básico, tienen rostros múltiples y su grado de marginación y opresión vara por su clase, color, etnia y sexo. A pesar de que esos pobres son sujelos diferentes, la lógica de exclusión los unifica. Su vida, en tanto amenazada, muestra públicamente un rostro desíigurado por la miseria y la humillación. Hablamos de deshumanización.

Se ha entendido justificación como sinónimo de humanización', esto es corecto. Sin embargo, generalmente se ha tocado sólo una dimensión psicológica del ser humano: el sentirse libre de culpa y reconocerse como sujeto finito sin la necesidad de autoafirmarse constantemente frente a Dios, los demás y él mismo ${ }^{7}$.

Esta dimensión no es suficiente en un mundo dividido y donde los excluidos imumpen en la historia. Hay una relación profunda entre la deshumanización psicológica — bajo la dimensión de sentir la necesidad de aprobación como ser humano-, y la deshumanización corporal, cultural y social; es decir, donde se palpan las huellas de la desnutrición y de la insignificancia.

La muerte ronda entre el hambre y la insignificancia Alli está el reinado del pecado, legitimado por la ley de la exclusión. Es un reino de muerte no porque esté muerto, sino porque mata; está vivo y su vida se mantiene al absorber $\mathbf{~ a ~}$ sangre de los excluidos. Se trata del fdolo $\rightarrow$ no falso sino verdadero- que se impone como sefior. La intención de su lógica no es matar en sí, pero como su justicia está orientada a dar vida a algunos de la humanidad, el resto queda excluido y su vida es amenazada por los vaivenes de las pulsaciones de la lógica que se sustenta por la exclusión. La angustia se afiade a la experiencia del hambre o a la amenaza de la vida".

Este reino de pecado, repetimos, tiene una lógica orientada hacia la muente y hacia allí arrastra todo lo que encuentra a su paso. Toda ley que eche sus raices en este reino está condenada a la atracción o arrasar de esa lógica, aun cuando la ley sea buena o intente orientar hacia la vida'. Por lo tanto, es un reino injustificable, que solo arrae sobre sf la ira de Dios. Pues, en definitiva, la verdad ha sido aprisionada en la injusticia como en tiempos de Pablo, por causa de su supuesta bondad y piedad

Detrás de esta realidad se lee una parodia teológica vinculada a la justificación gratuita, pero en su polo opuesto: justificación por los méritos. El sistema 
orientado con el criterio de rentabilidad y preferencia pregona la salvación por medio de la ley de la máxima ganancia (aclualizada hoy en la privatización). Es la ley del mérito. Todos aquellos que quieren ser reconocidos como sujetos dignos delante del mundo y salvarse deben someterse a la ley de acuerdo a sus propios recursos. Como la salvación se alcanza por méritos (sociales, económicos y culturales), muchos quedan fuera y se pierden. Estos son los "condenados de la tierra." No hay perdón para ellos, porque el sistema no conoce la dimensión de la gracia ni de la fe. Incluso la única propuesta de salida -el préstamo- conduce Lambién a la muerte, porque el pago de la deuda es la muerie ${ }^{10}$.

Este reino necrófilo, aunque apunta hacia la eternidad por su capacidad de acomodo y reajustes, lleva en su seno el germen de su propia condena a la destrucción total, no sólo la de los excluidos. Porque a la larga, esto equivale a muerte para todos. Al matar al ser humano y a su mundo que le rodea, se destruye a si mismo como humano" ${ }^{11}$. La deshumanización está presente, pues, no sólo en el pobre e insignificante, sino también en el asesino y poderoso. En el acto de matar se pierde toda calidad humana y se da lugar a la irracionalidad. No hay espacio para la afectividad, el amor, el sabor de la vida y los deseos de vivir.

Por eso, la sentencia de esta lógica es condena de muerte para todos: los asesinados y los asesinos. Condena a la nada, la muerte etema. Y esta sentencia, si se cumple, hace desaparecer a Dios mismo de la historia humana, porque Dios es Dios de vivos.

Sin embargo, a pesar de la potencia de este reinado, los que creen, como Pablo, que la gracia de Dios sobreabunda donde abunda el pecado (Ro 5, 20). dan cuenta de otra lógica impulsada por el Dios de vida. Su sentencia se resuelve en justicia para todos. Y la justicia de Dios se revela para que haya "vida en abundancia" (Jn 10, 10). Como es para todos, no hace elección, al contrario, reacciona contra las preferencias. Por amor al excluido, rechaza la condena a muerte tanto para el condenado como para el que condena a muerie ${ }^{12}$. Cuando rechaza la condena y dicta sentencia de vida para todos, la lógica condenatoria pierde su valor y se desvanece. Este anuncio es una afirmación promesa que pertenece al "tiempo largo"13; es escatológica y siempre válida en "los tiempos cortos" de la historia, para todos los que creen.

Por eso, antes de declarar la justificación, en el sentido clásico del término ${ }^{14}$, Dios hace una propuesta efectiva de vida para todos - justificación en términos biblicos-, y anuncio de muerte para el pecado. Justificación apunta a un proceso de vivificación, donde el promotor de la vida es "el que resucita a los muertos y llama lo que no es a ser" (Ro 4, 17). Esta es la promesa a la cual el excluido se aferra por fidelidad a sí mismo, es decir, a su condición de humano, o, lo que es lo mismo, por fidelidad a su creador. Creado por el Dios de la vida, con la vocación de vivir como hermano's y de dar vida el ser humano tiene como destino recuperar su humanidad auténtica (a imagen y semejanza del Dios 
de vivos), humanidad pisoteada por el otro, que también posee una imagen mutilada de Dios.

\section{b. La recuperación de la imagen de Dios}

La primera señal de vida es el redescubrimiento de la imagen de Dios en la humanidad ahogada por el pecado, alll donde acecha la muerte: en el hambre y la insignificancia. Se trata de sentir la pulsación de Dios "en los infiernos" y experimentar la gracia en el basurero' ${ }^{16}$.

El ser humano fue creado por Dios a su imagen y semejanza para vivir, convivir, y dar vida. En el momento que mata o es malado, la imagen divina se rompe en él; ocurre deshumanización y falta de Dios por este rompimiento. Ya que su tarea, la de reencontrar su vocación de vida, se da en una sociedad que la niega rotundamente por estar construida no con cimientos del Dios de la vida, sino alrededor de un idolo creado que exige sacrificios humanos ${ }^{17}$, dicha tarea se vuelve absurda y escandalosa para el incrédulo, y para el que cree, una empresa realizable sólo en los niveles de la imposibilidad. ¿Cómo encontrar la imagen de Dios en la muerte?

Para que los seres humanos recuperen su imagen humana auténtica, es decir, de Dios, no basta la sola idea de la revelación de su justicia pronunciada desde la eternidad. Esta tiene que manifestarse en las fronteras de la historia humana ${ }^{16}$. La justicia tiene que manifestarse en el cuerpo. Porque asi como la injusticia ensefia las heridas morkales, asf́ lambién la justificación ha de mostrar las marcas de la vida fecunda. El encuentro entre los seres humanos y Dios se hace, pues, imprescindible, en el espacio de los "tiempos contables". Habrá que recurrir a la humanidad de Dios'.

Aunque todos muestran una imagen rota de Dios (tantos los victimarios como las victimas), Dios escoge un lugar de encuentro para que su imagen se reproduzca en todo ser viviente. Elige no para excluir, sino precisamente para negar la exclusión; incluye a todos a partir de los excluidos. Escoge preferencialmente el lugar del excluido que grita a Dios su abandono, alguien que se sabe excluido y reclama al Dios de la vida su ausencia.

Alli en el grito del "Dios mío, ¿por qué me has abandonado?", o el de "¿Hasla cuándo?", o el de "¿Por qué?", se palpa la pulsación de la imagen divina en el hombre, que a pesar de rota, no ha sido borrada del todo. En este paso del hablar a Dios, - y no sobre Dios-, y de saber que El oye, se engendra la esperanza en la vida Son los deseos de vivir manifestados en el clamor de los oprimidos, que descubren la imagen de Dios, aquel que antes de hablar, escucha los dolores de su pueblo. Al sentirse escuchado, el excluido entra en diálogo con ese Dios atento y recupera su imagen divina que implica la dignidad del ser humano, de la persona, del sujeto. La fe en la factibilidad de la vida alumbra en él su imagen divina. 
Esta fe en la posibilidad de la vida tiene su asidero en la fe en la solidaridad de Dios. Y esta fe, a su vez, tiene asidero en la manifestación del Dios-humano. En la humanidad de Jesús encontramos a ese Dios solidario ${ }^{20}$. La misma revelación escrita la enserta. Hay una relación estrecha entre Jesús y los excluidos ${ }^{21}$. La historia de los excluidos la leemos en la historia de la vida y muerte de Jesús en la cruz, y esta historia, a su vez, nos revela en toda su crudeza este reino de hoy, que usurpa el puesto de Dios, desplaza al Hijo y rompe la imagen divina en el ser humano. La justicia de Dios se revela en la historia de la vida concreta de fe de Jesús de Nazaret, que murió y fue resucitado, y esa misma vida revela la injusticia del reino de la muerte, del pecado y de la ley.

La fuente de esta revelación de su justicia está en la fe en la resurrección del condenado a muerte en la cruz. No esta en la muerte en sí. Si estuviera en la muerte no hubiera diferencia con tantos crucificados inocentes de su tiempo, 0 incluso con los profetas. Tampoco está en la resurtección a secas, - -las religiones circunvecinas tenian dioses que resucitaban-, sino en el creer que Dios resucitó precisamente a aquel excluido que siendo justo a sus ojos (y a los ojos de los pobres), fue crucificado 22 .

Jesucristo es, pues, en la cruz el excluido por excelencia ${ }^{23}$. En el momento más álgido fue abandonado por todos, incluyendo a Dios y sus amigos. Allí grita Jesús su abandono, allí lleva el excluido los dolores de Dios ${ }^{24}$.

Pero all también grita Dios Padre su veredicto: juslicia y justificación para todos, en diametral oposición contra la condenación de muerte para los excluidos. El acto de la resurrección del excluido Jesús, marca la efectividad del veredicto de justicia para todos: la justificación (Ro 4, 25). Por este Jesús resucitado de la cruz, todos son hechos juslos. Somos justificados por los mérilos de Jesucristo, realizados en su práctica que lo llevó a la muerte. En oposición a Adán, es ésta su obra de justicia que procura toda la justificación (Ro 5, 18); es por su obediencia a la voluntad de vida del Padre que lodos son constituidos justos (Ro 5,19 ). El es, entonces, el primer resucitado (y justificado) de muchos. En él se hace factible la promesa de la resurrección del cuerpo de todos (ICo 15, 20s).

Los excluidos, al percatarse que su historia coincide con la de este Dios-humano, y que, teniendo la dignidad de un Dios, grita también como ellos, recobran la confianza en sí mismos. Toman conciencia de que no están solos, que Dios estŕ con ellos gritando al unísono, como lo estuvo en su Hijo. Brota allf la fuerza de la fe en aquel que vence la muerte de la cruz. El ser justificado implica, entonces, recobrar en la fe la imagen de Dios, la dignidad de ser humano creado para la vida y para recrear esta vida en justicia. Esta es la experiencia de la justificación por la fe, concedida en el juicio de Dios a su favor.

No hay cabida aqui para abrir un debate sobre fe u obras. La experiencia de sentirse ser humano digno, sujeto capacitado para tomar decisiones en la historia, y para no sólo resistir, sino transformar la realidad que lo mata, invoca 
solo a una experiencia de gratitud, a acoger la vida como un don que vale la pena defender porque allí se juega el todo del ser humano2s.

\section{c. La solidaridad como ralz de la justificación}

De acuerdo a lo mencionado arriba, la justificación como afirmación de la dignidad y justicia funda sus raíces en la solidaridad: Dios se solidariza con lo humano en Jesucristo, prototipo del excluido. Al hacerlo, convoca a todos los hombres y mujeres de la tierra a la práctica de la hermandad basada en su justicia. Es gracias a la solidaridad de Dios, manifestada en el primero de muchos hermanos, que el ser humano redescubre su imagen divina, como un ser justificado por Dios, y es por medio de la práctica de la solidaridad que la justificación se vuelve tangible ${ }^{26}$. Porque "...la praxis cristiana no es s6lo la consecuencia de la metanoia anterior, sino el modo de hacer esa mesanoia real y no meramente pensada o sentida"z?

Leemos la solidaridad como señal de la justificación en dos figuras: la solidaridad de amigos en el encuentro fecundo de dos logos o discursos: Dios-humano, y la solidaridad de hermanos (as) en el don de la filiación.

\section{1) Solidaridad de amigos, encuentro fecundo en la justificación}

Hemos hablado de la buena nueva de Dios y de la palabra del excluido. Son dos discursos. Uno, la afirmación escatológica de que se ha revelado la justicia en Jesucristo, y otro, el discurso inmediato del excluido: "Dios mío, Dios mlo, ¿por qué me has abandonado?". Estos discursos proceden de diferentes logos. Deben encontrarse para ser fecundos. Si estos dos discursos no se unen en una sintaxis común, serán palabras lanzadas al viento que no mostrarán más que la impotencia de una fe frustrada. La tarea en nuestro mundo actual es que el logos primero responda eficazmente al grito del segundo, y que el segundo reconozca en Dios su compañero solidario.

Para que se encuentren los dos logos —al margen de toda ingenuidad-, hay que considerar los tiempos y espacios.

El logos del excluido es un grito real, sale de la corporeidad desfigurada, del espíritu afectado por la insignificancia. Si lo humano se distingue por (a) compartir con otros el destino de la historia de todos y (b) tener acceso a la materia que nutre y a la celebración de la vida como gracia, difícilmente se distinguen en este logos los trazos de lo humano.

La palabra de la revelación de la justicia de Dios es real, pero no corporal. Es real, porque puede ser creída y asumida en la particularidad y, con ello, generarla en la hisioria humana (ver Jesucristo). El anuncio de la revelación de la justicia se muestra como "el sueño que da eficacia a la praxis"2s. Pero no es corporal, porque es gracia; es un don concedido como comunión e interpretación al 
que cree ${ }^{2}$. Tampoco es circunstancial, porque es un grito pronunciado desde la etemidad. Es universal y por eso su verdad sólo se muestra en las circunstancias y en lo corporal.

La revelación de la justicia de Dios y el grito del desvalido por exclusión se dan cita en el uiempo y el espacio de Jesucristo. Desde su niffez hasta el momento culminante de su muerte hay una relación solidaria mutua ${ }^{30}$, pero es la pasión el clímax del lugar común entre el Dios escondido y el excluido.

En este momento hislórico, los dos logos excluidos, con una imagen de Dios irreconocible $y$ sorprendente por la tortura y la insignificancia, son hermanados por el amor mutuo: amor del Hijo por el excluido y amor del excluido por el crucificado. El marginado toma conciencia de su imagen de excluido a semejanza de Dios. Y del amor solidario de ese Dios. Es fecundo por un amor cuya finalidad será la búsqueda de la vida para todos, y el rechazo de toda lógica de exclusión. Se trata nada menos que de la fuerza de la fe del pobre que cree en el pobre.

Allí encontramos la solidaridad de Dios desde el interior de la historia con los excluidos, y a partir de éslos con los demás. Aquel que es capaz de percibir y creer que en ese rincón escandaloso está la presencia discreta y solidaria de Dios, es capaz de ser amigo de Dios ${ }^{31}$. Dios lo llama amigo, como a Abraham. La solidaridad aqú es otra señal de vida, de imagen de Dios, es la respuesta al grito del excluido, primer signo de vida.

\section{2) Solidaridad entre hermanos, señal de la justificación}

Paradigma de la solidaridad de Dios por la fe es la urinidad No sólo por la relación perfecta de comunión entre Padre, Hijo y Espíritu Santo, sino, captóndola desde el ángulo de la justificación, por la obra de las tres manifestaciones divinas en el proceso mismo de la justificación.

Pablo lo percibe desde su situación. El Hijo encarnado, al asumir la debilidad y precariedad de lo humano en fidelidad al Padre, deviene el hermano de todos, y codos los que tienen fe en la vida entregada del Hijo se convierten en sus hermanos. Al convertirse ellos en hermanos del Hijo, el Espíritu se une a su esṕritu para pronunciar la palabra propia del hijo: $A b b a$, Padre (Ro 8, 15; ver Ga 4-6). Todos los que la pronuncian se hacen hijos de un Padre único que los adopta en su gracia. Todos, al obedecer a un mismo Padre, se convierten en hermanos entre si. Esto es, se consolida la fratemidad que defiende, comporta y celebra la vida como esencia y vocación del ser humano ${ }^{32}$.

Con esta figura se quiebra cualquier intento de individualismo egoísta. El ser humano en general es justificado precisamente para que se reconcilie consigo mismo, con su projimo, con Dios y con su medio, y para que lleve adelante el misterio de la reconciliación (2Cor 5,18 ). La solidaridad interhumana es señal 
de la solidaridad de Dios, raíz de la justificación. Sin ella no hay justificación alguna.

Ahora, la solidaridad auténtica no proviene de las obras de una ley que exige la justicia para alcanzar la jusificación. Si los méritos propios son requisito, no hay solidaridad real de Dios. La hermandad, el ser hermana(o), es un don que acogemos en la filiación gracias al Hijo; por eso es hecha con material divino ${ }^{33}$, inseparable del Espíritu Santo. Es un proyecto de vida sin fin, eterna, pero que ha de brotar desde ahora. La fratemidad es "el rostro" y "despliegue histórico de la filiación ${ }^{n 34}$. La solidaridad, pues, se opone a la ley exigente de méritos. Esta última marca una distancia entre el sujeto actuante y el sujeto amante; y corre el peligro de suprimir la espontaneidad del amor incondicional. La obra de la gracia (o de la fe) nace de la entrega libre de los hijos de Dios a su vocación de dar vida, vivir y celebrarla en gratitud. Un buen ejemplo del justificado esı́ en $\mathrm{Mt}$ 25, 31-46. Alli se ayuda al pobre por gracia, sin segundas intenciones, es decir, sin pensar interesadamente en que Dios esta presente en ellos y que a él se está sirviendo ${ }^{35}$. Incluso, si se hace por amor a Dios independientemente de la vida de éstos, se obra según la ley y no según la gracia. La solidaridad viene de la gracia y se desarrolla en la gracia ${ }^{36}$. Quien acuía por amor a Dios, para acumular méritos, niega la justificación graluita, porque sigue sometido al régimen de la ley y no de la gracia.

\section{d. La celebración comunitaria de la gracio}

Es verdad que escribir sobre la gracia hoy día es un desafio. Para hablar de la gracia de Dios en América Latina hay que introducirse en el mundo de los miserables y excluidos. Es difícil hablar desde afuera. Porque por más que se la busque, uno no encuentra más que des-gracia" ${ }^{3}$. La pluma objetiva tiende sólo a dibujar en la escribura la piel sedienta de su cuerpo que pide justicia. Los labios leen solo llagas de insignificancia e indignidad en la infrahumanidad del pobre y marginado. Por eso, hablar de gracia aquí con perdón de los pecados es una ironía para el pobre. Se necesita fe y coraje para poder percibir más allá de lo visible y de lo objetivo; se necesita imaginación para escribir desde la promesa de vida para todos. Sin esta dimensión, que ya es de gratuidad, la teología se tambalea cuando alcanza discemir la gravedad del pecado histórico actual y el cinismo de sus agentes. Y la exhortación al amor del projimo se queda colgando de un hilo o en la resonancia de un eco que la repite mil veces sin que haya sujetos que la consoliden eficazmente. Llega la desesperación y el fantasma del sentmiento de impotencia para "organizar la esperanza".

Pero lo fundamental no es reconocer la realidad de exclusión o de anti-vida, sino el tiempo propicio de salvación $n^{30}$ (Ro 3, 21; 2Co 6, 2). Esta noticia es motivo de gran alegría y solo es efectiva y placentera, a pesar del costo, en la comunicación y comunicación de esta noticia con los amenazados de vida. Pablo, 
al hablar de este tiempo propicio de salvación, invoca al ministerio a la reconciliación interhumana con un imperativo vehemente, ya que sin la reconciliación la gracia se torna vana (ver 2 Co 5,$20 ; 6,1-3$ ).

El que recupera su imagen divina de sentido a, o relativiza con objetividad, el sufrimiento, discieme las dimensiones de vida y muerte de su mundo y apuesta a la sobreabundancia de la gracia frente a la abundancia del pecado ${ }^{39}$. Esto es porque deposita su confianza en Dios, y puede, con la confianza que Dios le otorga a sí mismo, celebrar la vida en medio de la muerte. Puede hacerlo porque no cree en la victoria de la muerte, sino en el uriunfo de la vida para todos, garantizada por la resurección (1Co 15, 55-58).

Cuando los amenazados de vida y los que tienen fe en la solidaridad de Dios perciben este amor en defensa de su existencia celebran la vida como un don, como gracia No hay manera de hacerlo en secreto, individualmente; los excluidos son muchos y en cuanto se reconocen como tales y como favorecidos del Dios trino, se cuentan la historia de esta solidaridad y la festejan.

Esta memoria colectiva (memoria passionis et resurrectionis) de la solidaridad de Dios se celebra: "Hagan esto en memoria mia" (en la celebración y en la vida cotidiana) son palabras de Jesús que resuenan como desafío perenne y como acción de gracias en la comunidad. "Hagan esto en memoria mía" es más que el ritual de lo que llamamos "Cena del Seffor". Es compartir el pan y el vino en amistad ${ }^{40}$ en la comunidad crisliana y en la vida diaria, y el perdonarse los unos a los otros las ofensas. Es un evento plurisignificativo; como indica Julio de Santa Ana, es recuerdo de liberación, compromiso con el reino, misterio de la presencia de Jesús, alimento y fuerza; es motivo de obediencia a Dios y convocación a la esperanza"1.

Pero es también "mirar la muerte de frente" (la muerte particular y real de un inocente, el envidiado); es reconocer que el ser humano es capaz de matar injustamente a la luz de la legalidad. Es "confesar que matamos cuando rechazamos la vida en su verdad y realidad" 42 .

Celebrar la vida y la justicia como un don para todos sólo puede hacerse en comunión de iguales. No hay lugar para la lógica de la exclusión. Por eso se afirma, y con razón, que la gracia tiene un carácter intrínsecamente social y comunitario ${ }^{43}$.

Se puede celebrar la fiesta en la precariedad objetiva de la vida, porque en la justificación, el lugar de la tristeza y el lamento dio espacio a la confianza de Dios como amigo solidario. Aun más, la comunidad no está sola; en medio de los tiempos de la lucha y defensa de la vida, se tiene la certeza de que hay alguien que vigila en el tiempo vital del descanso".

La celebración comunitaria abarca la vida y el cuerpo. La justificación hace relación a la afirmación de la vida, y la vida hace relación al cuerpo. Una vida 
no se vive sin el cuepo y viceversa. Cuando se afirma la vida, se afirma el cuerpo. Cuando se afirma el cuerpo por gracia, vienen los deseos de vivir, de sentir la vida, del gusto por la vida ${ }^{45}$. Se cree entonces en la resurrección del cuerpo ${ }^{46}$ - cuerpo de la comunidad, que proclama la vida para todos, vela para que lodos la posean y la celebra en comunión; y cuerpo de la persona que la goza en toda su dimensión. En la fiesta de los oprimidos.

Según las Escrituras, la comunidad de los justificados por la fe es el cuerpo de Cristo (1Co 12, 12-30) -un cuerpo de cuerpos con vida"7 , porque está fundamentado en la resurrección. Son los cuerpos vivientes los que le dan la vida al cuerpo que los abarca. Pero es el cuerpo de la comunión eterna la que vigila, defiende y proclama el derecho a la vida de todos como don de Dios inalienable. La realidad de la trinidad es desafío siempre presente: es comunión que incita a viviria. Por naturaleza rechaza todo tipo de exclusión ${ }^{48}$. Por eso, ningún justificado por la fe puede aceptar ningún proyecto de vida que excluya vidas, ya que la exclusión misma niega la finalidad del proyecto que de por sí es comunitario. Es así que la lucha por la vida deja de ser una cargo maldito como la del primer Adán en la tierra estéril (Gn 3, 17). A pesar de su dureza, está marcada por la esperanza de la resurrección de los cuerpos. Nuestra Iglesia concreta actual está siendo desafiada a reafimar esta experiencia de vida y gracia entre sus miembros. Así también está desafiada a redescubrir las pulsaciones de Dios allí donde menos parezca que respira, para rescalar a los amenazados de vida, aun cuando no formen parte de su cuerpo. Estos, como todos lo amenazados de vida, son depositarios primigenios del anuncio de la justicia de Dios y de la justificación: vida para todos.

\section{Notas}

1. Ver los fragmentos considerados pre-poulinos: 1 Co 1,$30 ; 6,11 ;$ Ga $3.28 ;$ Ro 3.24 $26 \mathrm{a}, 4.24 \mathrm{~s}, 5.1 \mathrm{~s}, 8.34$; 2Co 5,21 , y orros.

2. El lector "añade" sentido a la reserva de sentido que el texto mismo posee. Ver Severino Croato, Liberación y libertad...., p. 10, y Carlos Mesters, Por Trás das Palavras (Petrópolis: Vozes, 1977) p. 131.

3. Ver el testimonio de Pablo en 2Co 4, 7-12.

4. En este sentido hacemos un quiebre en los acercamientos pasados y contemporáneos sobre la justificación. Reflexionamos, no a partir del "Hombre" genćrico, sino de los seres humanos concretos, hombres y mujeres que sufren las consecuencias del pecado estructural de nuestra sociedad, sea como victimas sea como victimsrios. El móvil dinamizador de esta propuesta teológica no es, pues, el de discutir si hay o no en el ser humano algo bueno, o privilegiar la fe a las obras, o justificar a Dios frente a la muerte de los excluidos. Como nuestra preocupación prinera es la condena a muerte de estos por el pecado estructural, nuestro móvil es subrayer la solidaridad de Dios en la justificación como una acción divina, interpeledore para L próstica de la justicia. Estamos conscientes de que tste no es "el sentido" de la justificación, sino uno entre oros, que intentu der respuesta a la problemática ec- 
twal.

5. F. Hinkelammert contrapone la satisfacción de las necesidades vitales a la satisfacción de las preferencias (elección de productos, lecnologia, etc.). Esta segunda "debe ser derivada y subordinada a la primera Si hay necesidades [sin satisfacer], las preferencias o gustos no pueden ser criterios de orientación hacia los funes. El criterio básico sólo puede serlo, precisamente, el de las necesidades.... La satisfacción de las necesidades hace posible la vida; la satisfacción de las preferencias, la hace agradable. Pero para ser agradable antes tiene que ser posible". Subrayado del autor. Crírica a la razón usópica (San José: DEI, 1984) pp. 240s.

6. El hombre - varón/mujer- llega a ser humano cuando se sabe reconocido como al por Dios, es Dios quien le hace persona en la justificación. Querer aleanzar con sus acciones este reconocimiento va contra sí mismo, y puede perder su humanidad (Eberhard Jüngel, "Home Humanus. La signification de la distinion reformatrice entre la personne el ses oeuvres pour la fagcon dont thomme modeme se comprend lui-même". Revue de Theologie et de Philosophie, vol, 119, 1987, p. 48s). Para González Faus, la justificación paulina es "la transformación del hombre de inhurrano en bueno, $y$, por lo tanto, en plenamente humano". El autor señala que no hay una palabra que sustituya univocamente y de manera adecuada la palabra justificación, pero en el "horizonte semántico modemo", puede sustituirse por" realización humana", "humanización", "rehabilitación", y otros. Proyecto de hermano. Visión creyente del hombre (Santander: Sal Terrae, 1987) p. 487.

7. Ver el documento Justificarion Today (Helsinki, Lutheran World Federation, 1965) sobre el ser humano secular en la sociedad de competencia, I, 1, y la Iglesia acbual institucionalizada, II, 9. IV, 4. Ciertamente esa afirmación es bíblica y la explicitamos varias veces. Pero hay distintos ángulos que pueden asumirse. Karl Barth asume el ángulo genérico universal. Piensa la justificación a partir del Hombreanthropos: todos pecaron igualmente- Lodos de igual manera necesitan de la justificación. Se trata fundamentalmente del hombre pecardor, injusto, orgulloso, IV/ 1** \$ 61, 2, p. 197. Otros acercamientos actuales, impactados por el pecado actual visible en los mecarismos de opresión, parten del ser hum mo tambien como pecador, pero mís específicamente, para anunciar la gracia de Dios, parten en primera instancia del que oprime y derrama sangre inocente. De alll la insistencia en que ese ser reconozca su culpa, ya que peca contra Dios y contra el hermano. Ver González Faus, Proyecto...., pp. 393-414. De acuerdo a este mismo autor, es el pobre quien hace que el hombre y la mujer se conviertan al Ser̃or, porque le muesta la vedad del ser humano: que es pecador, y muestra asimismo el amor de Dios, porque este le justifica a pesar de su condición. "Los pobres como lugar teológico", on El secuestro de la verdad (Sentender: Sal Terrac,) 1986, pp. 138-143. Por eso se afima calegóricamente que el pecado fundamental es el de la aubafirmación o el de querer ser como Dios. Nos parece que este es un aspecto importance de la jusificación. No obstante, nosotros queremos, por ahora, partir de la sangre derramede, es decir, "de Abel", y no "de Caín". Porque nuestra pregunte es la misma que la de G. Gutierrez: "¿Cómo agradecer a Dios el don de la vida desde una reslided de muerte temprana $e$ injusta?, ¿como expresar la alegria de saberse amado por el Pedre, desde el sufrimiento de los hermanos y hermanas?". Beber en su propio pozo (Lima: CEP, 1983) p. 19.

8. La engustia que dimirula la vida de Lutero, debido a su insegurided de su salva- 
ción eterna, se traduce ahora en la angustia que experimentan los pobres en su vida concreta amenazada por el hambre, la represión y la insignificancia.

9. El problema que Pablo observó en la práctica de sus contemporáneos del primer siglo es que incluso aquellos que tenían una ley justa y santa, eran incapaces de hacer la justicia, en el antiguo eón.

10. Ver Raúl Vidales, "Pagar es morir, queremos vivir", Pasos (1987) n. 6.

11. Pablo Richard escribe: "El pecador va muriendo en su pecado. Hay un lf́nite. Cundo llega a ese límite, el pecado mata al pecador. Todo criminal se transforma en bestia y la bestia termina matando al criminal". La fuerza espiritual de la Iglesia de los pabres (San Jose: DEI, 1987) p. 124.

12. Cuando se habla de anor preferencial de Dios por los pobres, es porque precisamente se opone a la actitud de marginación. Su amor efectivo consiste en que no haya más pobres. En el cumplimiento del amor al próximo se busca la superación de favoritismos discriminatorios.

13. La terminologla "tiempo largo" y "tiempo corto" la tomamos de Sergio Spoerer. América Latina: los desafios del tiempo fecundo (México: Siglo XXI, 1980), y de Raúl Vidales, Utopía y liberación: el amanecer del indio (San José: DEL, 1988). Nosotros le damos una connotación teológica; eternidad-historicidad; universalidad-particularided.

14. Perdón de pecados y declaración exclusiva de justicia forense.

15. Proyecto de hermano y proyecto de hijo de Dios se corresponden; el ser humano es hermano porque es hijo de Dios. González Faus, Proyecto..., p. 12.

16. En defunitiva este es el drama que se plantea Gustavo Gutiérrez en Hablar de Dios desde el sufrimiento del inocente (Lima: Cep, 1986). ¿Como hablar del amo de Dios en medio de tan profundo desprecio por la vida humana? Para el, "Job seitala una pauta a través de su vehenente protesta, su descubrimiento del compromiso concreto con el pobre y con el que sufre injustamente, su enfrentamiento con Dios y a través del reconocimiento de la gratuidad de su proyecto sobre la historia humena", p. 223.

17. Para Julio de Santa Ana, las leyes del mercado "libre" se traducen en violencia sacrificial, "Costo social e sacrificio aos ídolos", en Divida ederna e igrejas. Uma visan ecumenica" (Río de Janeiro: Cedi, 1989), pp. 82. Dussel Identifica el idolo con el capital: "El capital tiene la pretención, como un verdadero dios, de producir ganancia, 'desde la nada' (ex nihilo). Su carécter idolátrico, fetichiste, ignora el origen de todo el valor que contiene, que ha acumulado. Cree que es ell mismo el que lo ha producido. La persona del trabajador es nada en dicho proceso". Elica camunitaria (Buenos Aires: Paulinas, 1986) pp. 145. 173.

18. La revelación de Dios, su nombre, esti siempre ligada a una hisloria que da a conocer a Dios: historia de liberación, de muerte y de resurreccion, de envio al mundo. K. Blaser, Esquisse de la Dogmatique (Lausanne: UNIL, 1985) p. 14.

19. Hacie el final de su vida Karl Barth (1956) hablo de la humanidad de Dios. Lastimosamente poco se conoce esta afirmación de Barth, la divinidad de Dios tiene caricter de humanidad en tanto que la manifiesta no en el vacto de un ser-para al diviro, sino que lo hace en el hecho de que existe, habla y achin como compailero del ser humano. "La humanidad de Dios", Eneryas teolbgicos (Barcelonr: Herder, 1978) p. 17.

20. Ver L. Boff, Pasión de Cristo-Pasión del mundo (Santunder. Sal Tarae, 1980) p. 
12. El himno cristológico de Flp 2, 5-11 ilustra este pasaje de la solidaridad de Dios.

21. "Jesús no está solo en la cruz, -escribe L. Boff en un poema en ponugués-. Están sus seguidores. Asumen su causa, imitan su vida y siguen su destino. Hay también el ejército de los crucificados. Ellos son invisibles. Están crucificados en el otro lado. La cruz tiene siempre dos lados, el del maestro, el de los discípulos y el de todos los sufridos de este mundo. Todos ellos están en el corazón de Jesús". L. Boff-Nelson Porto, Francisco de Assis. Homen do paraiso (Petropolis: Vozes, 198). Los asesinados desde el comienzo del mundo viven con Jesús. L. Boff, Passión de Cristo...., p. 231.

22. El evento de la justificación está en que Jesús fue resucitado como prueba de su inocencia frente a la condena (ver J. P. Miranda, Marx y la Biblia (Salamanca: Sígueme, 1975, p. 223); porque su condena a muerte en la cruz es la consecuencia de su vida de fe. Jon Sobrino, Cristología desde América Latina (México: CRT, 1977) pp. 150-162.

23. El Jesuctisto crucificado revela jdentidad de Dios: "Poder de los débiles" que se pone de lado de las víctimas de la historia, "esa es su identidad". K. Blaser, Esquisse...., p. 15.

24. Jon Sobrino hace ver el escándalo de este abandono de Dios y cómo la tradición desde sus inicios intento darle un sentido positivo al por qué de la cruz y se centró más en Jesús como el hijo de Dios y su poder. Se ha olvidado, añade, de la verdad cristiana de que Dios mismo estaba en la cruz de Jesús; y esto ha generado como consecuencia el no buscar a Dios donde él esté, "que cristianamente no es sólo la resurrección, sino la cruz, y en su versión histórica no es la belleza, el poder, la sabidura, sino las cruces reales de los oprimidos". Cristologla desde América Latina (Mexico: CRT, 1977) p. 150.

25. Como dice G. Gutiérrez, la experiencia de la gratitud del amor de Dios - dato primero de la fe cristiana- no sólo se sitúa como en un parénlesis histórico, sino que da al devenir humeno -y desde dentro-, su wotal significación". Beber...., p. 169. En este sentido, "creer en Dios será, en última instaneia, vivir nuestra vida como don suyo y ver codo lo que en ella ocurre como manifestaciones de ese don". ibid., p. 166. No se ignora con esto la consistencia propia de la historia, insiste G. Gutifrez; al contrario, se penetra en su sentido más hondo. Idem.

26. Pablo en Ro 8, 29 afirma que somos destinados a "reproducir la imagen" del Hijo de Dios, para que éste sea el primogénito entre muchos hermanos. Ser prinogénito significa: "que Jesís es el primero en quien se ha superado la contradicción humana y se ha terminado la creación: es principio de la realidad nueva", y también significa que "Cristo es la mela de toda la acción creadora de Dios... Es inagen que en la realidad actual, anuncia a la futura". Gonzf́lez Faus, La humanidad nueva (Santande: Sel Terrae, 1984) pp. 290s.

27. Jon Sobrino, Cristologla..., p. 6. Sobrino hace esta afumación cuando critica las cristologlas que tienen como punto de partida el Cristo del Kerygma, ya que en el Cristo predicado "no aparece ningún contenido concreto que garantice la autencided o ineutenticidad de la existencia", ibid., p. 5. Para nosotros la proclamación del kerygma esta intimamente relacionedo con la praxis del proclamador, seguidor sincero de Jesís. El Jesús histórico está presente en el kerygma no sólo porque la cruz nos conduce a 61 , sino porque él predicador actualiza la vida de Jesús. El testi- 
monio de Pablo es un ejemplo concreb. Hasta él mismo lo expreso cuendo escribib que vive la muerte de Cristo en la came para que la vida se manifieste a los oyentes del kerygma (2Co 4, 10-12), y que mostraba en su cuerpo las señales de Jesús (ge 6, 17); ver también Col 1, 24.

28. Frase de Rubern Alves, pronunciada en un dílogo con su comunidad; Campinas, Brasil, 26 de febrero, 1989.

29. González Faus hace ver el problema en la historia del pensamiento cristiano de haber considerado la gracia como "una cosa" o "substancia", en lugar de en terminos de relación personal. Proyecto..., p. 526. Ver también todo el pasaje, pp. 487-527.

30. En el llanto del niño-Dios, pidiendo leche de Marla (ver Rubem Alves, "Fome de Deus- Fome do homem", Pai nasso. Meditacôes (Sāo Paulo: CEDI-Paulinas, 1987, p. 103-107); en su amistad dignificadora con la mujer; en momentos de trabajo agotador con los marginudos y de descanso gratificante con los tachados de pecadores; en momentos de sucños y temores con la compañía de sus discipulos; y en momentos de agonla.

31. En el drama representado por Job y sus amigos, ninguno de estos dos fue capaz de reconocer la presencia de Dios en el basurero, hasta que Dios se revelo con un rostro dilerente al c:-perado.

32. Ver G. Gutiérrez, La fuerza historica de los pobres (Lima: CEP. 1979) pp. 27-29.

33. Gonźllez Faus, Proyecto...., p. 650.

34. Ibid., p. 651.

35. Como señala X. Pikaza: "lo que antes parecla doble movimiento (por un lado repartir los bienes a los pobres y por ouro seguir a Jesús) termina estando unido: a Jesús se le descubre en el servicio universal de ayuda a los necesitedos". X. Pikaza, Hermanos de Jesús y servidores de los más pequeños. Mi 25, 3/-46 (Salamanca: Sígueme, 1984), p. 308.

36. G. Gutiérrez, Beber..., p. 169.

37. L. Boff, Gracia y liberación del hombre (Madrid: Cristiandad, 1978) p. 18s., 4850.

38. G. Gutiérrez, Beber..., p. 36.

39. Lo nuevo en América Latina, dice G. Gutiérrez, no es el sufrimiento del pobre, sino la toma de conciencia del por qué de su pobreza y el deseo de salir de ella. Ese es el tiempo propio de salvación, Beber..., p. 36.

40. Según Julio Santa Ana, "compañero" viene de "compañla", término que a su vez viene de latín cum y paris. "En la cena se establece un compañerismo intimo con el Espíritu de Jesús y entre los participantes". Pan, vino y amisrad (San Jose: DEI, 1985) pp. $104 \mathrm{~s}$.

41. Ibid., p. 12.

42. Pierre Gisel, "Le Sactifice", Foi es Vie, vol. 83 (1984) p. 66.

43. González Faus, Proyecio..., pp. 665s.

44. Es aqu了 donde R. Alves opone el humanismo mesiánico al mesianismo humanístico. Este último cae en el ansia, dominado por la obsesión mesínica respecto a su poder para hacer la historia. Este no vive la vida en gratuidad. En cambio, el humanismo mesiánico preserva desde su experiencia histórica tanto la gracia como la creatividad. La creatividad de Dios asegura la creatividad del ser humano; ambos construyen el futuro. Religión, ¿opio o instrumento de liberación? (Montevideo: Tierra Nueva, 1970) pp. 223-241. 
45. R. Alves, Religión..., Pp. 238-241.

46. Ver los poemas de R. Alves en Creio na resurreiçâo do corpo (Sâo Paulo: CEDI. 1982).

47. El bautismo simboliza el paso a la nueva vida (ver Ro 6, 1-14).

48. L. Boff, La Trinidad, la sociedad y la liberacibn (Madrid: Ed. Paulinas, 1986) pp. 118, 287. 